\title{
Review of Fault Types, Impacts, and Management Solutions in Smart Grid Systems
}

\author{
Mohammed Mousa' ${ }^{1}$, Sherif Abdelwahed ${ }^{2}$, Joni Kluss ${ }^{1}$ \\ ${ }^{1}$ Electrical and Computer Engineering Department, Mississippi State University, Starkville, MS, USA \\ ${ }^{2}$ Electrical and Computer Engineering Department, Virginia Commonwealth University, Richmond, VA, USA \\ Email:mam1576@msstate.edu,sabdelwahed@vcu.edu, joni@ece.msstate.edu
}

How to cite this paper: Mousa, M., Abdelwahed, S. and Kluss, J. (2019) Review of Fault Types, Impacts, and Management Solutions in Smart Grid Systems. Smart Grid and Renewable Energy, 10, 98-117. https://doi.org/10.4236/sgre.2019.104007

Received: March 16, 2019

Accepted: April 27, 2019

Published: April 30, 2019

Copyright (c) 2019 by author(s) and Scientific Research Publishing Inc. This work is licensed under the Creative Commons Attribution International License (CC BY 4.0).

http://creativecommons.org/licenses/by/4.0/

\section{(c) (i) Open Access}

\begin{abstract}
Fault management study in smart grid systems (SGSs) is important to ensure the stability of the system. Also, it is important to know the major types of power failures for the effective operation of the SGS. This paper reviews diverse types of faults that might appear in the SGS and gives a survey about the impact of renewable energy resources (RERs) on the behavior of the system. Moreover, this paper offers different fault detection and localization techniques that can be used for SGSs. Furthermore, a potential fault management case study is proposed in this paper. The SGS model in this paper is investigated using both of the Matlab/Simulink and the Real Time Digital Simulation (RTDS) to compute the fault management study. Simulation results show the fast response to a power failure in the system which improves the stability of the SGS.
\end{abstract}

\section{Keywords}

Detecting Fault, Fault Management, Impact of Renewable Energy Resources, Isolating Faulty Load, Locating Fault, Matlab/Simulink, RTDS, Smart Grid System, Types of Faults

\section{Introduction}

According to [1], the SGS enhances the performance of the power grid and it improves the stability of the network. The SGS has more components that distinguish the system from the conventional power system. Also, the SGS can depend only on RERs to deliver power to the loads in the system. Equally important, the SGS is known to operate as a grid-connected system where loads receive demanded power from the grid and the RERs, and it can operate as a stand-alone system where loads receive power only from RERs. Figure 1 shows 
some major components of a conventional SGS: utility, photovoltaics (PV), wind turbines (WT), battery storage system, power converters, electric vehicles, smart communication devices, smart meter, switches, coupling point, and customers or loads of the system. Also, it is important to know that the SGS consists of two major networks that are linked together. According to [2] [3], the two coupled networks are the power network and the communication/control network in which they perform the framework of the SGS. The major components of the power network are energy resources, transformers, transmission lines, distribution lines, substations, and customers or loads. In contrast, the function of the communication/control network depends on the electricity provided by the power network. To illustrate, the power network must be controlled by the communication/control network in the SGS.

There are multiple improvements that the SGS provide compared to the conventional power system including improve power quality and availability, ensure system survivability and security, and reduce costs for customers. Also, the transient stability of the system should be improved in an ideal SGS. In addition, the robustness of the SGS is improved because of power controllers in the system. To illustrate, controlling the active power and the reactive power helps to improve the power angle and the voltage stability of the system respectively. Moreover, a droop controller can be used to enhance power sharing, where a secondary controller is used to reduce voltage and frequency deviations in the SGS [2] [4] [5] [6] [7]. Therefore, the SGS improves the maintainability of currents and voltages in the SGS within safe ranges.

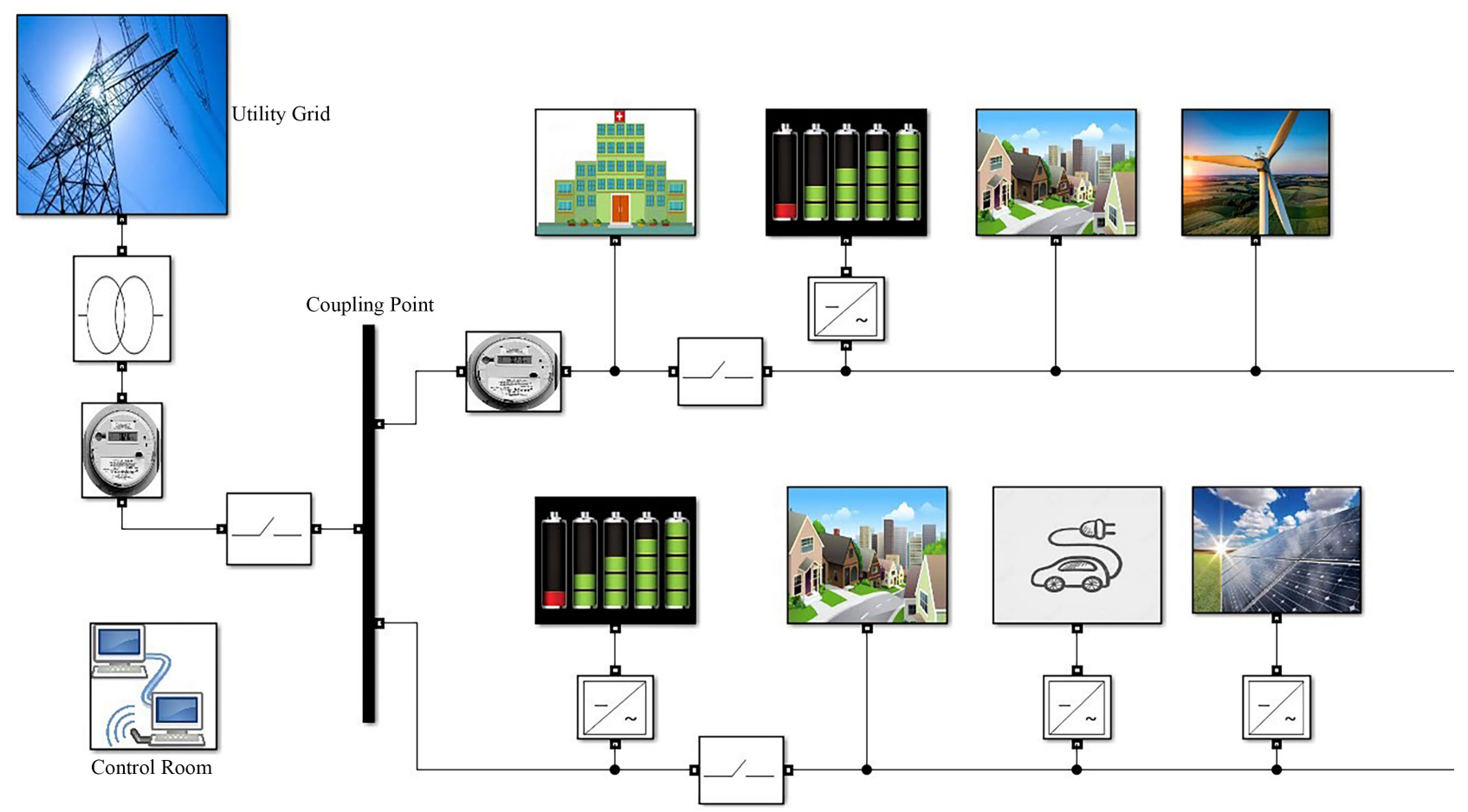

Figure 1. Major components of a smart grid system. 
The location of power failure and its type have different undesired impacts on the system performance such as power outages and component failures. This fact makes it necessary to recognize possible power failure causes and recognize different ways to clear out these possible failures to guarantee the stability of the system [4] [8]. Authors in [9], state that smart meters can be used to detect and locate unsafe current and voltage signals in the system since they consider fast response devices. Since the SGS is able to operate as a stand-alone system, it is preferable to isolate the main grid from the system to protect components in the SGS upon detection of faulty conditions [4].

According to [10], both of the survivability and reliability of the SGS are improved due to the existence of RERs in the system. In case of emergency conditions, the least priority loads are deposed from the system during the time of resolving the power failure. Shedding loads in the SGS occurs in the order of their importance. Survivability is defined as the ability of the SGS to provide demanded power to important loads in the system for both normal and faulty conditions. In short, the SGS is subject to face most of the power failures that occur in the traditional power system [1] [11]. Therefore, the survivability and reliability of the SGS are enhanced due to the existence of RERs, storage systems, and controllers in the system.

The importance of fault management and diagnosis, protection categories, common power failures, and proposed power failure categories are explained in Section 2. Section 3 discusses the impact of RERs on the performance of the SGS. Section 4 presents promising methods that can be used to detect and locate power failures in the SGS. The proposed system and computational software including Matlab/Simulink and RTDS are explained in Sections 5 and 6 respectively. Fault management simulation results including fault detecting, locating, and isolating faulty line using both software are presented in Section 7 followed by paper conclusion on Section 8 .

\section{Power Failure in the Smart Grid System}

\subsection{Importance of Fault Management and Fault Diagnosis}

According to [9], in order to maintain the normal operation and protect system components, fault management and diagnosis must be fast. Fault management techniques relate more to the communication network of the SGS. Moreover, fault management is essential to reduce synchronization problem and to improve the system economically. However, most fault management techniques require a control room to monitor and analyze the behavior of the system during the run time, as well as fault indicators, local automation, and communication devices. In addition, it is important to detect and locate the fault in the SGS rapidly enough to avoid a complete breakdown in the system [12] [13] [14]. According to [9], there are several fault diagnosis techniques can be used in the SGS including the intelligent devices that monitor current and voltage signals in the system. Another technique to diagnose faults is using the wavelet analysis or 
Markov model analysis to analysis the latest sensing data over the system [15] [16] [17]. This technique requires using smart meters distributed among the system, not only at load ends to diagnose faults in the SGS. Therefore, SGS should provide instantaneous diagnostic information and reasons for faulty conditions in the system.

\subsection{Protection}

Protecting the system components is important to keep the reliability of the system. According to [4], the structure of SGS allows it to detect over-current and over-voltage events in the SGS especially at the storage battery in the system and at the converter circuits. Moreover, in case of short circuit or high impedance faults, the SGS should operate in a stand-alone mode to protect the power network [4]. The protection scheme can be divided into three levels as shown in Table 1. Moreover, digital relays are used for distribution lines protection in the power system with the cooperation of the global positioning system to isolate faulty lines [18]. Thus, the SGS should follow the three levels of protection to prevent major components failure in the system.

\subsection{Power Failure in Smart Grid}

According to [19] [20], high-speed wind, flying objects, falling trees, physical contact by animals, lightning, snow storms, contamination of insulators, human errors, overloads, bad insulation, and protection failure are some reasons of faults in the SGS. Also, the balance three-phase SGS has the majority of power failure studies as reported in [10]. In addition, power failure is defined as an abnormal electric current in the power system which split into two types [19]. The first type is the external fault such as open circuits or short circuits such as phase-to-ground or phase-to-phase types of faults. The second type is the internal fault which may occurs at the storage system, DC bus, or at the AC side of the converter [4] [8]. To sum it up, the power failure in the SGS has unpredictable locations since it can occur at the generating side, transmission side, or at the load side of the system.

\subsection{Common Types of Power Failures}

According to [20] [21], external power failure that occurs in the power network of the SGS is categorized into two types. The first one is the series fault (open circuit fault) that occurs when two conductor (phases) open in the system due to a broken line. The second type is the shunt fault (short circuit fault) which occurs when two or more phases come into contact to the ground or to each other. According to [20] [22], 75\% - 80\% of failures in the power network of the power circuit are either a line-to-ground short circuit fault or transient fault. Single line-to-ground faults are the most occurring type of fault in power systems. Moreover, the shunt fault is classified as a balanced fault (symmetrical fault) or as an unbalanced fault (unsymmetrical fault). Listing the short circuit faults in order from most common to least common are: 
Table 1. Protection levels.

\begin{tabular}{|c|c|c|c|}
\hline & Warning & Isolating & Shutdown \\
\hline Indication & $\begin{array}{l}\text { Unusual behavior that } \\
\text { exists but does not have } \\
\text { immediate } \\
\text { harm to the system }\end{array}$ & $\begin{array}{l}\text { Separating part of the } \\
\text { system for protection } \\
\text { purpose }\end{array}$ & $\begin{array}{c}\text { Prevents } \\
\text { Fault that may cause damage } \\
\text { if left uncorrected }\end{array}$ \\
\hline $\begin{array}{l}\text { Needed } \\
\text { equipment }\end{array}$ & Communication devices & $\begin{array}{l}\text { Relays, breakers and } \\
\text { switches }\end{array}$ & $\begin{array}{l}\text { Relays, breakers, } \\
\text { and switches }\end{array}$ \\
\hline
\end{tabular}

- Phase-to-ground

- Phase-to-phase

- Two phases-to-ground

- Three phases

- Three phases-to-ground fault

\subsection{Power Failure Categories}

For this paper, faults in the SGS are categorized into three types: incipient, abrupt, and intermittent faults. According to [23], an incipient fault is considered an arc fault that lasts for a harmless period of time in the SGS. Authors in [24], described the abrupt fault as the abrupt signals change due to power failure in the system [24]. Finally, the intermittent fault is a short duration transient that is deemed to be an incipient event which leads to a permanent fault in the system [25]. There are several reasons for these types to occur such as severed conductors, loose contacts, or wire degradation. These three aforementioned power failure categories can appear at different locations in the SGS and result in serious power problems. These types may appear at transformers, induction motors, underground cables, or at transmission and distribution lines. Moreover, they are able to cause electric fires or fuel tank explosions ignited by arcs and sparks, power interruption, system damage, or power outages. On the other hand, conversion of an incipient fault to a permanent failure is a gradual phenomenon and may take several months. The SGS will perform and behave normally as if no interruption occurs, after a short duration of transient time. This fact makes it necessary to detect these aforementioned types of fault early stages [23] [24] [25] [26] [27]. As shown above, there are several factors that can cause the three mentioned types of fault, in which their impact may last for a long period of time without causing major accidents.

There are different techniques which deal with incipient, abrupt and intermittent types of faults. First to mention is the wavelet transform analysis which is used to detect and classify incipient faults by detecting the amplitude and duration of a disturbance in the system [23]. In addition, to detect and locate an incipient fault in underground cables, the impedance-based distribution method is recommended [26]. For intermittent faults, distance relays are used to monitor changing conditions which help detect intermittent faults [24]. Another method to detect an intermittent fault in the system is monitoring the carrier signal be- 
tween buses in the SGS [25]. Finally, to detect abrupt changes in the SGS, digital relays or the wavelet transformative and adaptive filter method can be used as reported in [24]. Equally important, authors in [28], reported that the temporary deviations of the load circuit model coefficients and wiring parameters is a promising method to detect arc fault in the system. Moreover, to detect arc faults, a comparison of reference load currents and measured load currents can be used [27]. In short, the power failure in SGS is categorized into three types in this paper. This section explained promising techniques to deal with these types of power failure in the SGS. However, the detecting methods are considered sensitive to frequency, size of the power system, and they require communication techniques.

\section{Impact of Renewable Energy Resources on the Stability of a Smart Grid System}

According to [12], to ensure the stability and the reliability of the SGS under steady and transient operations, there are several factors must be acknowledged including the location of the RERs in the SGS, integrating RERs to the power grid, topology of inverters in the system, frequency deviation, cascading failures, the structure of the storage system and much more. To illustrate, the fast response of RERs and their locations in the SGS affect the dispatch mode based on the penetration level [12]. In a grid-connected SGS, integrating RERs at low voltage level increase the possibility of power failure in the system due to the bidirectional power flow [19] [29]. Variation of active and reactive power due to RERs in the SGS leads to a change in current and voltage fluctuations which affect the stability and reliability of the system [30]. Also, the stability of the SGS is affected by the topology of inverters in the system as reported in [28] [31]. Moreover, the oscillation of the SGS can be affected by the change of the damping ratio of RERs depending on control parameters including the gain of real and reactive power [13]. The frequency deviation leads to drop some loads in the system after tripping generators. This event occurs during post-fault conditions when the SGS switch from grid-connected to the stand-alone mode of operation [32] [33]. Equally important, cascading failures lead a severely conditions. The cascading failure can be split into two types: the load propagation failure that occur due to an overloaded in the SGS, and the interdependent failure that occurs due to the nature of the relation between the two networks [2]. Moreover, the uncertainty from RERs affects the cascading failure and increase the number of load shedding and tripped lines in the system [34].

Availability of generated power from RERs is not certain due to the topology of the SGS, sensitivity of components, possibility of equipment failures, changes in weather, and much more. Also, it is important to acknowledge that lack of equipment maintenance and undesired weather such as high speed wind could cause fires, damages in systems' components, and they put the systems stability and human safety under threat. For example, a failure of a single PV cell can se- 
verely affect the output of a whole string which may lead to fire or power losses of the PV module [22] [35] [36]. Additionally, weather fluctuation affects the operation of PVs which increase the level of danger in the system [37]. Also, high speed wind affects the gearbox, frequency, and the reactive power generated by the WT [38] [39]. Therefore, the structure of RERs has an impact over the operation of the SGS.

\section{Detecting and Locating Faults in the Smart Grid System}

\subsection{Techniques to Detect Different Faults in the Smart Grid System}

Fault detection techniques must be fast enough to detect a power failure in order to keep the stability of the system. The following are explanations of different methods that some researchers studied to detect different types of power failure in the system. Measurement devices can be used to read important data at every node in the system which helps in detecting abnormal changes in the system. According to [4] [39], voltages and currents in the power network must be maintained within safe limits during faulty and normal operation, and they must be self-adjustable to pre-event values to ensure the stability of the system during faulty conditions. However, measurement units can be negatively affected by the size of the power network, so the efficiency of these fault detection techniques can be affected by the size of the power network too. Another method to detect a fault in the system is using the data-driven computational approach based on machine learning as mentioned in [1]. Also, phasor measurement units can be used to determine the response time after the current exceeds its safe limit which helps to detect the fault in the SGS. Yet, the phasor measurement unit could not provide enough information about the power failure in the system [40] [41]. Furthermore, the Petri Net method is used to detect a power failure in the SGS. This method requires measurements of transient voltages and voltage sags during faulty conditions in the system. On the other hand, the Petri Net method can face a strong penetration of distributed generators in the system [42] [43]. Authors in [44] discussed the possibility to detect fault in the system by combining the wavelet analysis with neural network or support vector. But, the wavelet analysis requires a high sampling rate which causes it to decrease the accuracy of the method [44]. Moreover, changes in system matrices of the state space model can be used to detect a fault in the system, where the small changes can be detected using the Local Optimum method and the large changes detected using the Generalized Likelihood Ratio method as explained in [45]. Authors in [46], state that the fault can be detected by studying changes in the impedance characteristics after injecting a high-frequency current to the system. The weakness of these techniques is that they require high-quality smart meters in order to accurately detect these changes in the system [45]. Although there are a considerable amount of researches investigates fault detection methods to improve the stability of the power system, they still have weakness points that can be addressed for improvement. 


\subsection{Techniques to Locate Different Faults in the Smart Grid System}

It is important to locate the geographical position of power failure in the system to deal with it in order to keep the stability of the system after detecting a fault incident [9]. According to [10], there are several techniques are used to locate a fault in the system. Figure 2 shows a diagram helps to choose some promising techniques to locate the power failure in the system [10] [47]. According to [11], frequency component and line parameters are used in the phasor-based method, while transient components of signals and distributed line parameters are used in the time-domain based method to locate a fault in the SGS. To illustrate, the phasor-based method depends on the traveling waves for high-frequency components and it depends on the phasor quantity for fundamental frequency. On the other hand, the time domain-based method depends on expert systems, neural network, or fuzzy logic to locate power failure in the SGS. Moreover, phasor angle measurements across buses in the system are used in the Gaussian Markov method to locate the fault [1] [11]. Authors in [48], state that inspecting lines in the system from one or two ends can be used to locate the fault using the source impedances. According to [4] [11], voltage sags and swell measurements can be used to locate a fault in the SGS which appears in the system during a short circuit event, switching off a large load, switching on or off a large shunt capacitor bank, switching off a transmission line. The Root Mean Square (RMS) voltage in the faulty line decreases during the faulty condition which is known as the voltage sags, and the RMS voltage in the un-faulty line increases to determine the voltage swell. Another method to locate the fault in the system is the State Estimate which is a mathematical method. It is used to determine voltages in every node in the SGS and only analysis faulty current with considering current from the main grid and ignoring all other sources as mentioned in [10] [49]. It is important to know that most of these presented methods are subject to lack of accuracy based on the size of the power network.

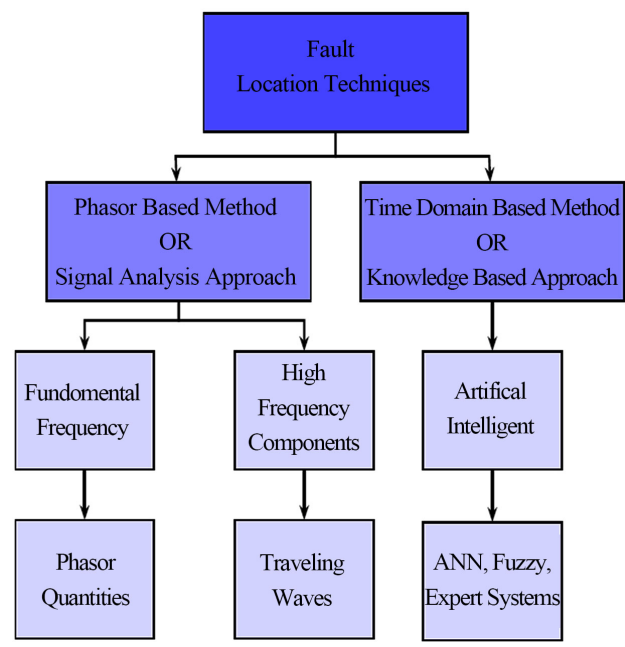

Figure 2. Fault locations techniques. 


\section{The Investigated Smart Grid System}

The proposed SGS is validated by [50] as shown in Figure 3. It represents a three buses SGS which supplies a small town, and consists of a $100 M V A$ power plants, a $275 K V A$ WT, a 200 kilometer transmission line and approximately 5 $M V A$ loads. Table 2 represents the parameters of the transmission line. According to [8] [49], voltages and currents change should be within (+/-) $10 \%$ to keep the stability of the system. This fact is applied in this study to detect power failure after current exceeds rated values at any location in the system. Moreover, the location with the highest increase of faulty current during faulty condition is considered the faulty load in this study. Equally important, power failure must be detected within $10 \mathrm{~ms}$ - $50 \mathrm{~ms}$ and located within three cycles. It is important to isolate the faulty load after three cycles to ensure the stability of the un-faulted parts of the SGS [8] [49]. In addition, indicators $P 1, P 2, P 3$ and $P 4$ in Figure 3 represent the measurement locations which are defined as the substation (SS), wind turbine (WT), load 1 (L1), and faulty load (L4) respectively. These measurements units used to provide the measured currents at each location during normal operation, faulty condition, and after isolating the faulty load. Indicators $S 1, S 2, S 3$, and $S 4$ represent the circuit breaker which programmed in Matlab file to isolate the faulty load after determining the faulty location. Matlab/Simulink allows the user to choose the type of fault and the location to apply it in the system. A three phase-to-ground is considered the most severe type of power failure and it applied to the proposed SGS at $t=1 s$ and cleared at $t=2 s$ where the system runs for $3 s$. The location of the fault is at the distribution line of load 4. Furthermore, the system has been investigated in RTDS to ensure the robustness of the proposed fault management technique. The RTDS platform allows users to apply fault at the desired time during runtime.

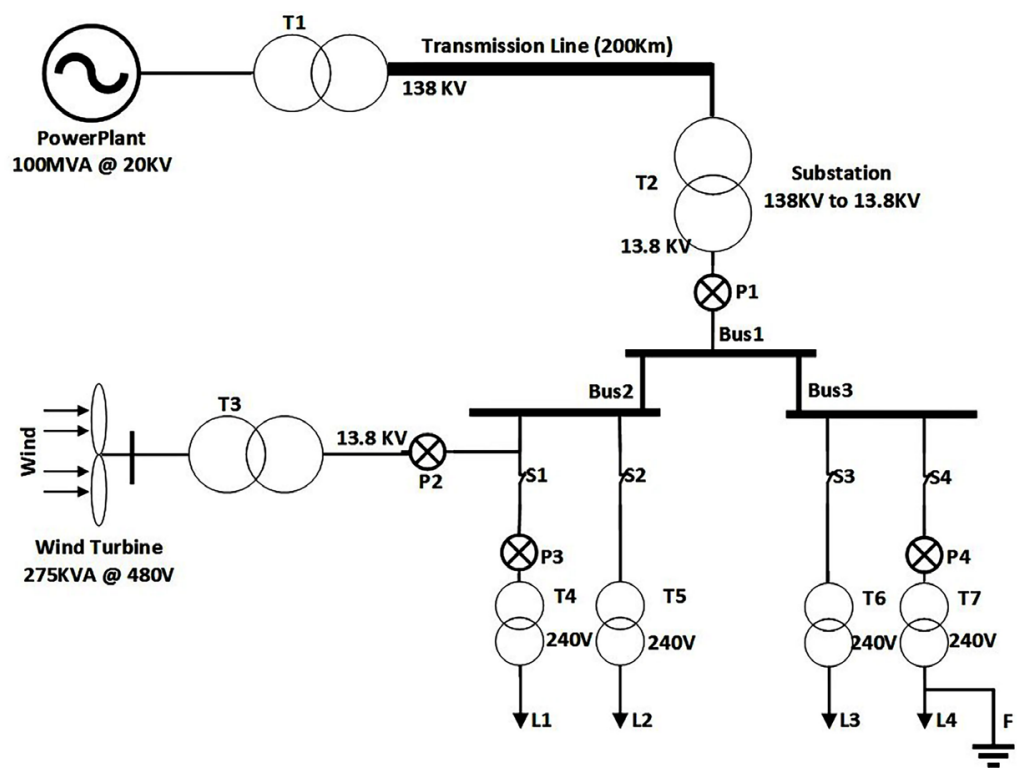

Figure 3. Proposed smart grid system. 
Table 2. Transmission line parameter.

\begin{tabular}{cccccc}
\hline$R 1$ & $R 0$ & $L 1$ & $L 0$ & $C 1$ & $C 0$ \\
\hline$(\Omega / k m)$ & $(\Omega / k m)$ & $(H / k m)$ & $(H / k m)$ & $(F / k m)$ & $(F / k m)$ \\
0.012 & 0.386 & $0.933 \mathrm{e}-3$ & $4.126 \mathrm{e}-6$ & $12.7 \mathrm{e}-9$ & $7.75 \mathrm{e}-9$ \\
\hline
\end{tabular}

\section{Simulation Softwares}

\subsection{Matlab Simulink}

There are several softwares used to test power systems. Matlab/Simulink and RTDS/RSCAD are wildly used software in terms of protection and control power systems including SGSs. Moreover, these softwares have a large library of components which make it handy for users. According to [51], the Matlab design is known as Matlab file ( ${ }^{*}$.fig). This Matlab file consists of a coded program using Matlab language which stores as $\left({ }^{*} . \mathrm{m}\right)$ file, and a power system designs in Simulink model and stores as ( ${ }^{*}$.SLX) file. These files interface to run the system and provide user with simulation results for user's study. Thus, user can build and run the system in Matlab Simulink; where he/she can code and control the designed system using the Matlab/Code. Figure 4 shows the proposed system in this paper as designed in Matlab Simulink.

\subsection{Real Time Digital Simulation}

RTDS is a digital power system simulator that consists of advanced computer hardware and softwares which operates in real time [52] [53]. The RTDS has been proven as an ideal protection and control tool to build and design power systems and SGSs. According to [53], procedures in RTDS are executed in parallel which makes it be considered as a fast processor simulator. The RTDS in utilized by the RSCAD, which is a Graphical User Interface. In addition, the RSCAD has a wild library that makes it capable to simulate a SGS. RSCAD software consists of two major environments linked together which allow users to run and execute the simulated model. First, the draft allows the user to build the system and compile it and check for compilation errors. After compiling the model without errors, the model will be able to run in the second environment known as the Runtime of the RCSCAD software. RCSCAD has a library of components that allows users to control and interact with the simulated model such as push bottoms, controlling switches, meters and much more. In case of using breakers, switches should be used to control opening and closing breakers in the Runtime file [53]. Moreover, a hardware in the loop (HIL) can be implemented in the RTDS. The hardware can be a PV or a relay. In fact, the RTDS provides HIL scheme, but it does not include communication interface [54]. Furthermore, user can introduce more functions and events to the system at runtime after translating the system to a $\mathrm{C}$ program using the Unified Modeling Language (UML) in RSCAD. This feature allows users to communicate and link RTDS to RSCAD. So, users can apply more condition statements such as for loop, if-else, and while statements [52] [55]. This fact has been implemented in 
this paper to isolate faulty load after three cycles from detecting a power failure in the system. The power failure determined after current exceeds rated values. According to [8], current must not exceed rated values which are determined as $(+/-)$ 10\%. Figure 5 presents the interacting between the RSCAD, draft, runtime, and RTDS. Therefore, the RTDS interface with the RSCAD isolates faulty load and ensures the protection in the SGS. Detail steps to complete the study in this paper are as follows:

- Measure current at all locations $P$ and store them as $I_{P}^{\text {rated }}$.

- Apply the short circuit fault.

- Detect fault when current exceeds $I_{P}^{\text {rated }}$ at any location $P$.

- Re-measure currents at all locations $P$ and store them as $I_{P}^{\text {fault }}$.

- Calculate rate of change at all locations $P$ as $\Delta I=\left|I_{P}^{\text {fault }}-I_{P}^{\text {rated }}\right|$.

- Find the location $P$ with maximum rate of change $(\max (\Delta I))$ and consider it as faulty location.

- Isolate faulty load using the circuit breaker associate with faulty line and re-measure currents at all locations $P$.

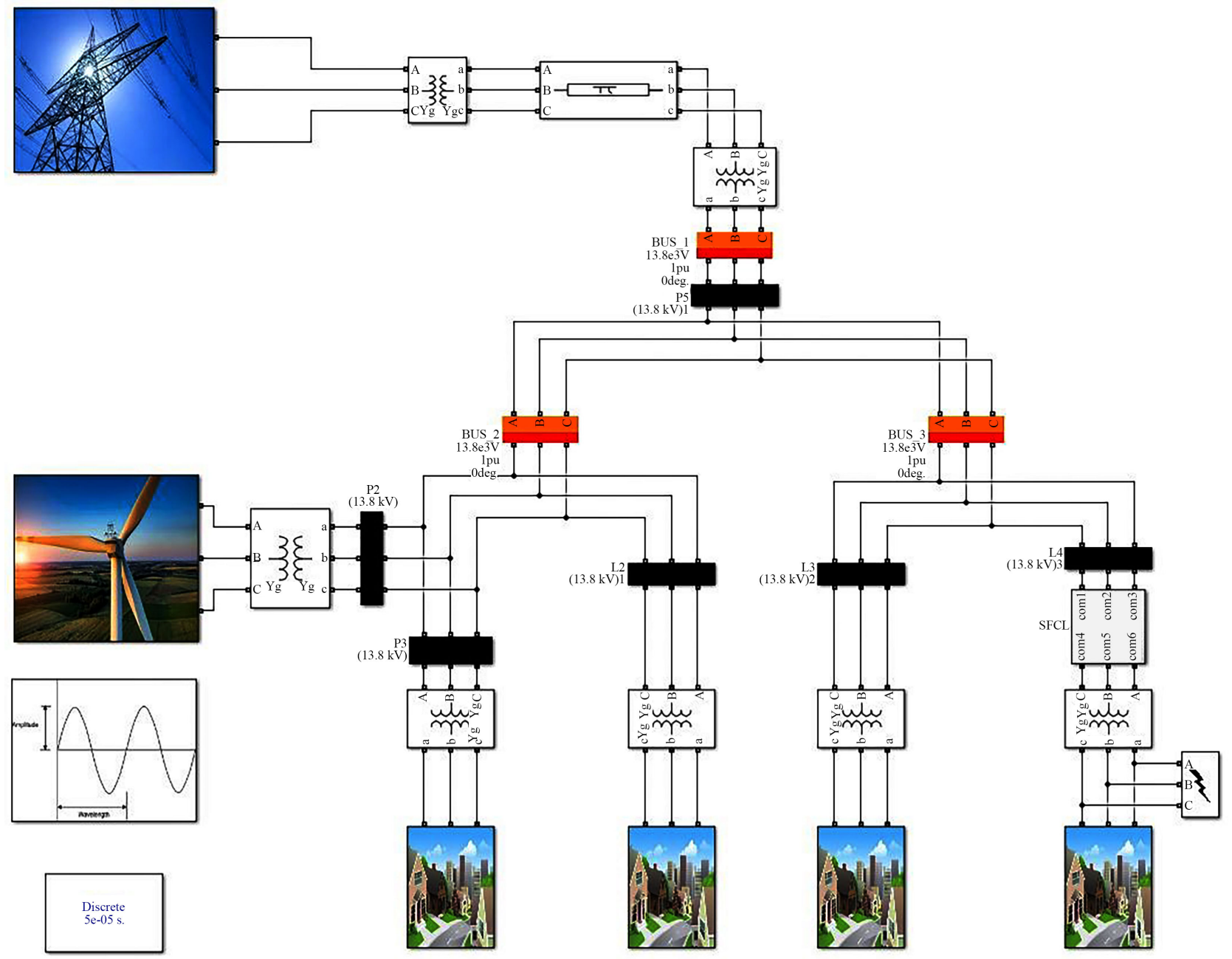

Figure 4. Proposed smart grid system/Matlab-Simulink. 


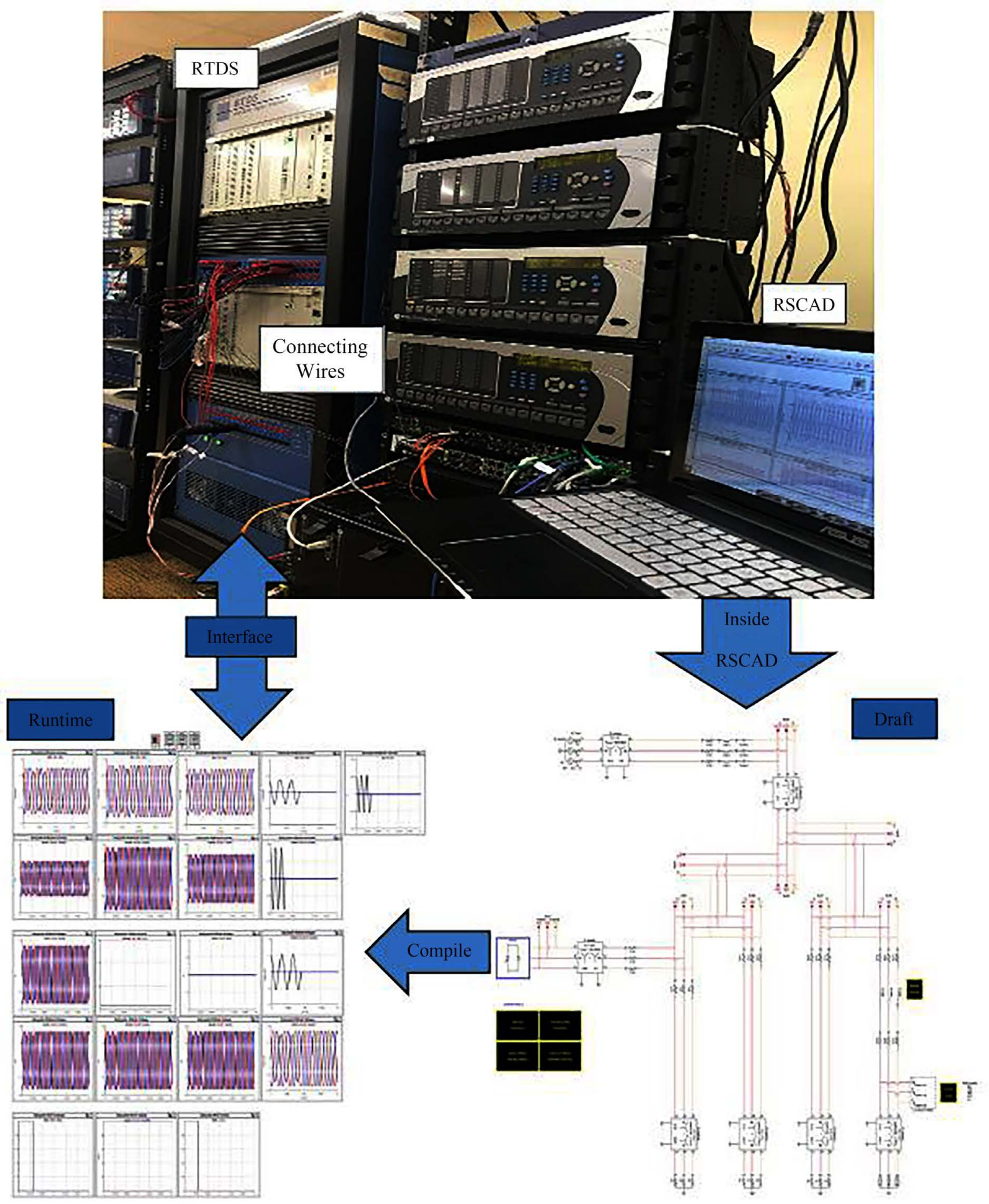

Figure 5. RTDS setup to interface with RSCAD.

\section{Simulation Results}

\subsection{Matlab Simulink}

Figure 6 depicts current at SS (Ia-SS), WT (Ia-WT), L1 (Ia-L1), and at L4 (Ia-L4). Currents at load 2 and load 3 measured similar to load 1. Also, it is observable 
that currents increase during faulty condition, and returned within their acceptable ranges at $S S, W T$, and $L 1$ after isolating the faulty load from the SGS. Current at $L 4$ return to zero after isolating faulty line.

Figure 7 illustrates current values at all locations $P s$ for all three conditions which are currents before fault, during faulty condition, and after isolating faulty load. Figure 8 shows the time needed to detect the fault at $L 4$ after applying the fault in the system. The pre-event rated current at this location measured as 350.3 Amper, and the highest safe limit at this location is 385.3 Amper. The fault detecting time is found to be equal to $12 \mathrm{~ms}$ which is the time when the current exceeded the limit at this location and the time at the peak of the pre-event value. Moreover, a protection warning should be provided at the time when the faulty condition detected. The highest increase of faulty current was measured at L4 which indicate the faulty location in the system. The rated current at L4 was 350.3 Amper and the faulty current reached 954.5 Amper. Figure 9 shows the current waveform at L4 during normal operation, faulty condition, and after isolating the load from the system. Also, it can be shown how the faulty load L4 was isolated after three cycles as shown in the same figure.

\subsection{RTDS Results}

The behavior of the results that excluded in RTDS met with results of the SGS designed in Matlab/Simulink. RSCAD allows user to apply fault during the runtime. The fault is applied to the system and the current waveform displayed in Figure 10. Moreover, Figure 10 shows the time needed to detect the failure in the SGS as designed in RTDS. The peak value of the last normal signal measured at $0.026 s$ as $389 A$ and fault current exceeded maximum rated current 383 at $0.040 \mathrm{~s}$. The system needed about $14 \mathrm{~ms}$ to detect the fault. Figure 11 shows that faulty line isolated after three cycles within $45 \mathrm{~ms}$.
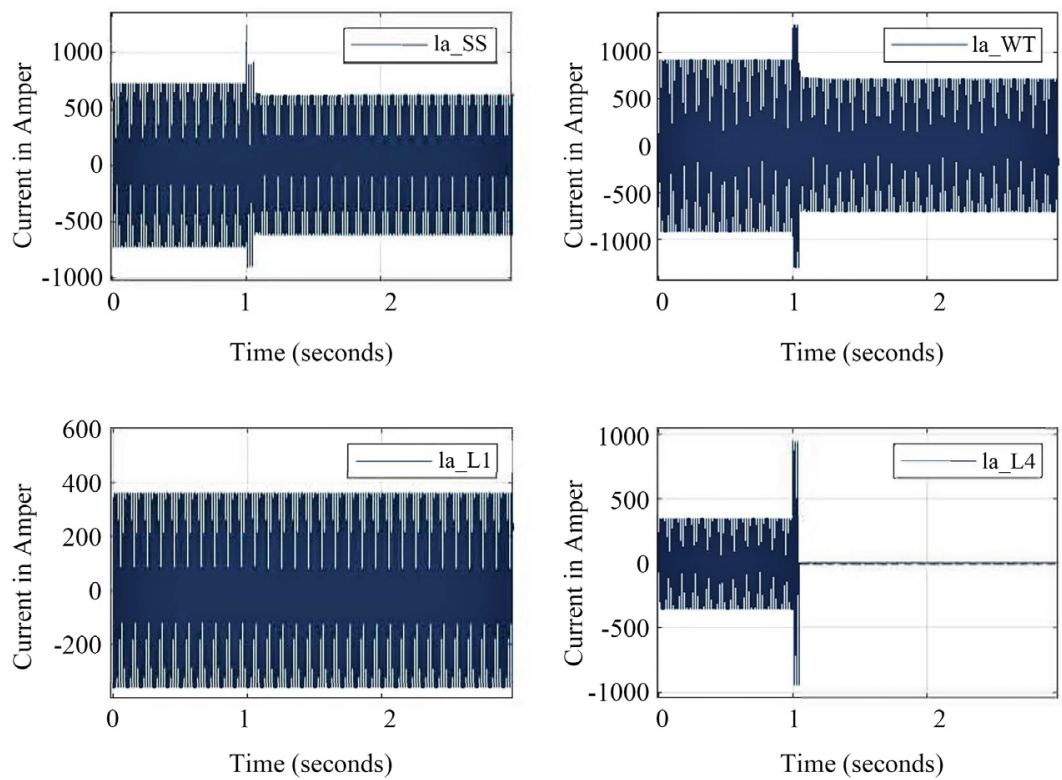

Figure 6. Current at all locations $P$. 


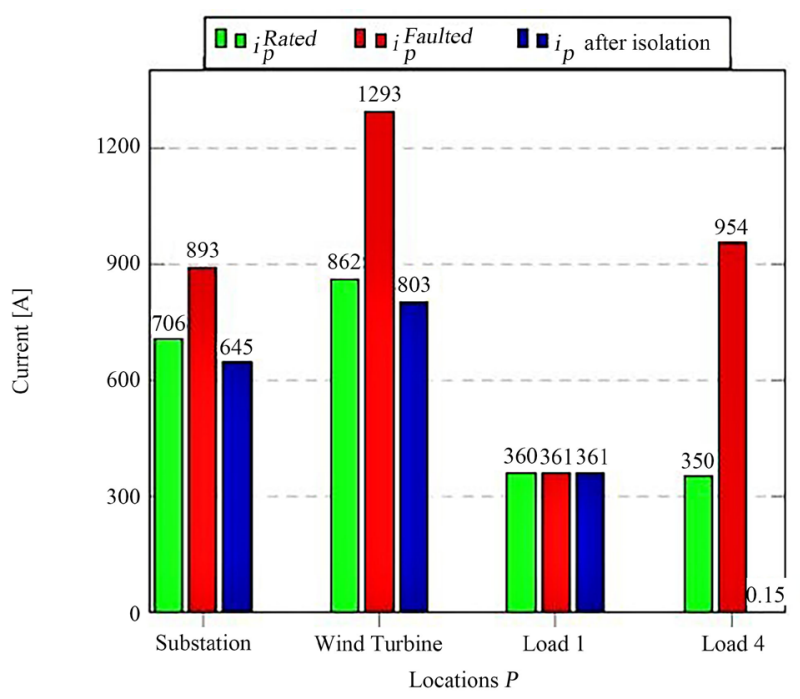

Figure 7. Measured currents at all locations $P$ before fault, during fault condition, and after isolating faulty load.

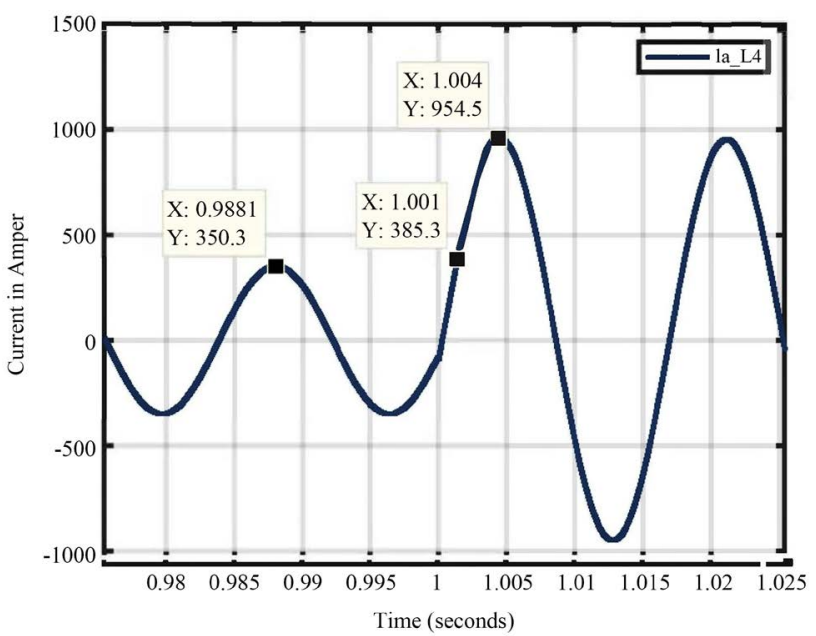

Figure 8. Current waveform at faulty load during fault condition using Matlab/Simulink.

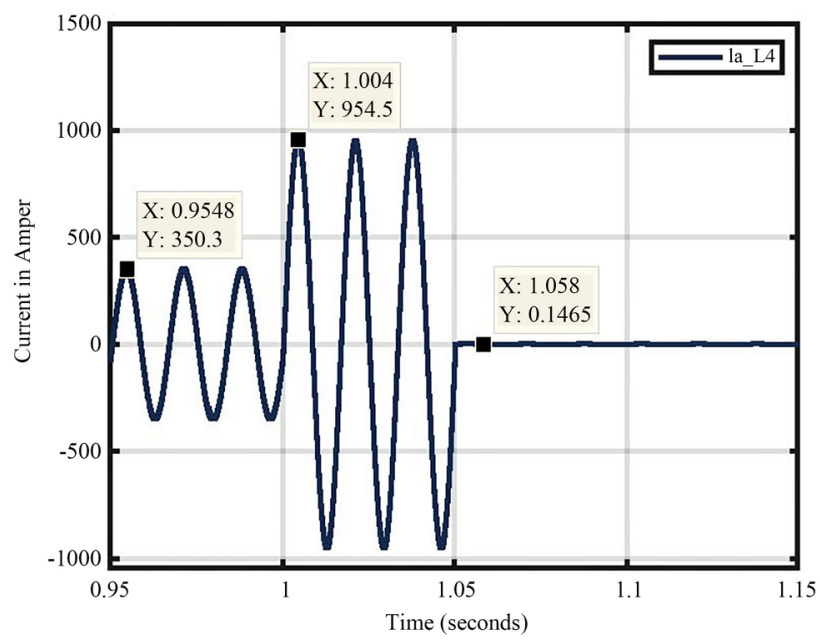

Figure 9. Isolating faulty load after three cycles using Matlab/Simulink. 


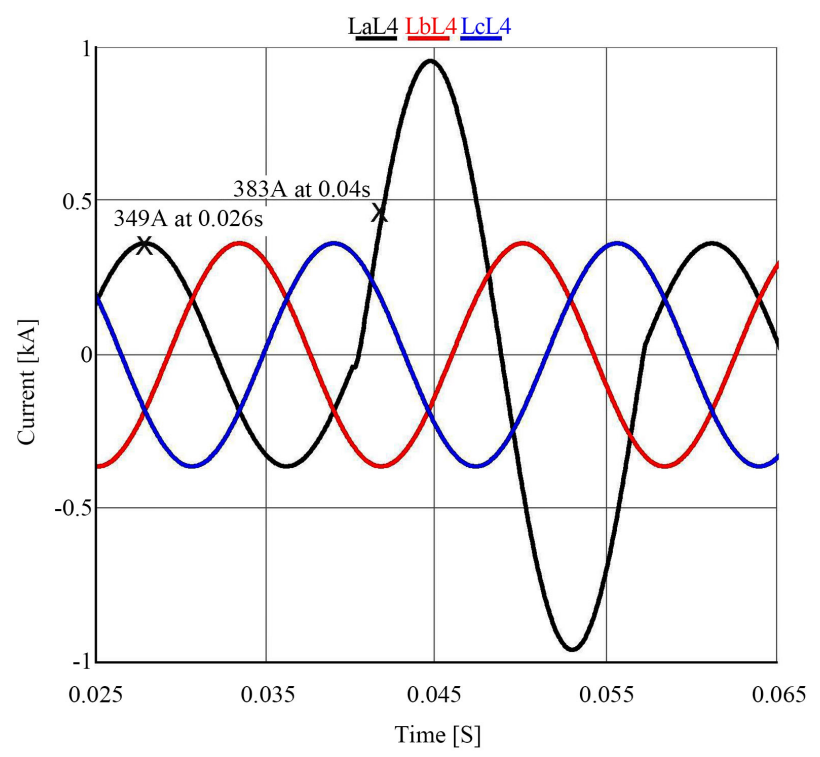

Figure 10. Current waveform at faulty load during fault condition using RTDS.

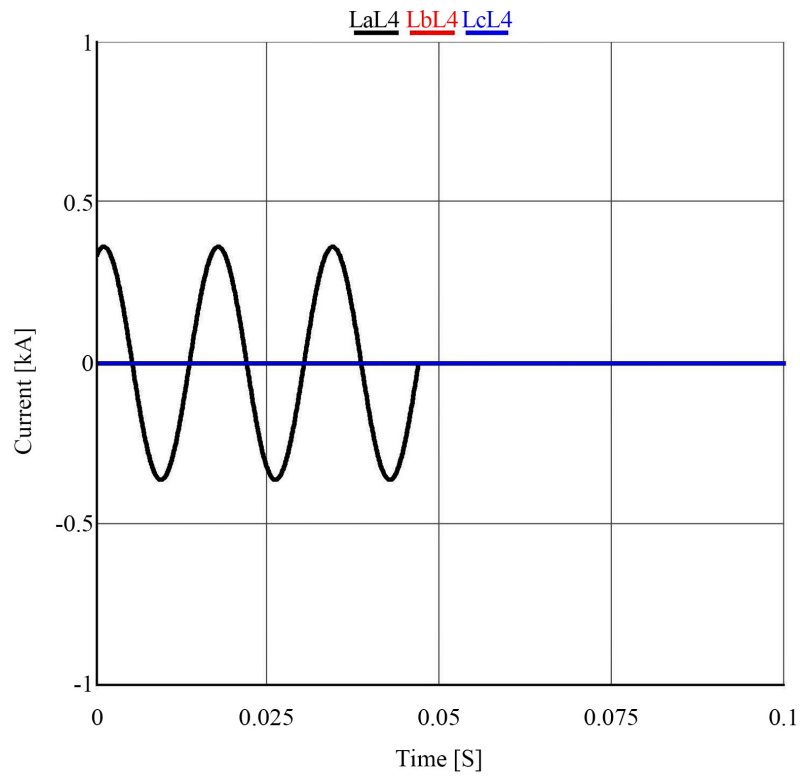

Figure 11. Isolating faulty load after three cycles using RTDS.

Table 3, concludes the time taken to detect the faulty condition in the system, the faulty location, and the time needed to isolate the faulty load after three cycles in both simulation softwares which are the Matlab/Simulink and RTDS.

\section{Conclusion}

This paper discussed failures in the SGS from different aspects. First, this paper discussed the topology of the SGS and what distinguishes the SGS from the conventional power system. Also, the impact of RERs on the stability of the SGS is explored in chapter 3. Then, power failures in the SGS including reasons of occurrence, types of power failures, protection, and fault management are illustrated 
Table 3. Results table.

\begin{tabular}{cccc}
\hline & Detecting Time & Faulty Load & Isolating Load \\
\hline & $(\mathrm{ms})$ & Location & $(\mathrm{ms})$ \\
Matlab & 12.9 & Load 4 & 50 \\
RTDS & 14 & Load 4 & 45 \\
\hline
\end{tabular}

in this paper. Immediate response to power failures is important to protect components and to avoid power outages in the SGS. Fault management study including detecting, locating, and isolating faulty line has been investigated in this paper using Matlab/Simulink and RTDS software. Both softwares are explained in this paper. A phase-to-ground short circuit fault was applied to the SGS and was detected within milliseconds which allow initiating a warning to operators. Measured currents at locations $P$ are used to locate the fault in the SGS. After that, faulty line was isolated from the system using breakers for protection purposes. This study applies a grid-connected SGS. Simulation results show the importance of shedding faulty load and improving the stability of the SGS to reach customer satisfaction. To sum it up, this paper focuses on illustrating different types of power failures that are subject to occur in an SGS along with promising solutions to these types of faults. Also, a fault management including fault detection, locations and isolation of faulty line has been investigated in this paper by using Matlab/Simulink and RTDS softwares. For further study, more details about fault in the communication/control network of SGS could be provided. Also, a physical relay could be interfaced with the RTDS software to form a HIL study. The HIL will enhance results about fault detecting and isolating. Therefore, studying power failures in the SGS from different aspects are important for stability study of the SGS.

\section{Conflicts of Interest}

The authors declare no conflicts of interest regarding the publication of this paper.

\section{References}

[1] Jiang, H., Zhang, J.J., Gao, W. and Wu, Z. (2014) Fault Detection, Identification, and Location in Smart Grid Based on Data-Driven Computational Methods. IEEE Transactions on Smart Grid, 5, 2947-2956. https://doi.org/10.1109/TSG.2014.2330624

[2] Huang, Z., Wang, C., Zhu, T. and Nayak, A. (2015) Cascading Failures in Smart Grid: Joint Effect of Load Propagation and Interdependence. IEEE Access, 3, 2520-2530. https://doi.org/10.1109/ACCESS.2015.2506503

[3] Mousa, M.A., Abdelwahed, S., Batiyah, S.M. and Qunais, T. (2017) Impact of variation of Energy Resources on Voltage Stability of a Micro Grid. 2017 Saudi Arabia Smart Grid (SASG), Jeddah, 12-14 December 2017, 1-8. https://doi.org/10.1109/SASG.2017.8356480

[4] (2005) IEEE Guide for the Functional Specification of Medium Voltage (1 kV - 35 
$\mathrm{kV}$ ) Electronic Shunt Devices for Dynamic Voltage Compensation. IEEE Standards 1623-2004, 1-17. https://doi.org/10.1109/IEEESTD.2005.96096

[5] Qunais, T. and Ghartemani, M.K. (2019) Systematic Modeling of a Class of Microgrids and Its Application to Impact Analysis of Cross-Coupling Droop Terms. IEEE Transactions on Energy Conversion, 99, 1. https://doi.org/10.1109/TEC.2019.2904182

[6] Hasan, M., Sourabh, S. and Parida, S. (2016) Impact of a Microgrid on Utility Grid under Symmetrical and Unsymmetrical Fault Conditions. 2016 IEEE 7 th Power India International Conference (PIICON), Bikaner, 25-27 November 2016, 1-6. https://doi.org/10.1109/POWERI.2016.8077384

[7] Batiyah, S., Zohrabi, N., Abdelwahed, S., Qunais, T. and Mousa M. (2018) Optimal Control Design of a Voltage Controller for Stand-Alone and Grid-Connected PV Converter. 2018 IEEE Texas Power and Energy Conference (TPEC), College Station, TX, 8-9 February 2018, 1-6. https://doi.org/10.1109/TPEC.2018.8312094

[8] Mousa, M., Abdelwahed, S. and Kluss, J. (2019) Impact of Resistive Superconductive Fault Current Limiters Location and Its Resistance Value on the Stability of Micro Grid System. 2019 IEEE Texas Power and Energy Conference (TPEC), College Station, TX, 7-8 February 2019, 1-6.

https://doi.org/10.1109/TPEC.2019.8662153

[9] Rajaei, N., Ahmed, M., Salama, M. and Varma, R.K. (2015) Fault Current Management Using Inverter-Based Distributed Generators in Smart Grids. 2015 IEEE Power \& Energy Society General Meeting, Denver, Colorado, 26-30 July 2015, 2183-2193. https://doi.org/10.1109/PESGM.2015.7286397

[10] Cordova, J. and Faruque, M.O. (2015) Fault Location Identification in Smart Distribution Networks with Distributed Generation. 2015 North American Power Symposium (NAPS), Charlotte, NC, 4-6 October 2015, 1-7. https://doi.org/10.1109/NAPS.2015.7335105

[11] (2010) IEEE Recommended Practice for $1 \mathrm{kV}$ to $35 \mathrm{kV}$ Medium-Voltage DC Power Systems on Ships. IEEE Standards 1709-2010, November 2010, 1-54. https://doi.org/10.1109/IEEESTD.2010.5623440

[12] Liu, J., Zhang, W., Zhou, R. and Zhong, J. (2012) Impacts of Distributed Renewable Energy Generations on Smart Grid Operation and Dispatch. 2012 IEEE Power and Energy Society General Meeting. San Diego, CA, 22-26 July 2012, 1-5. https://doi.org/10.1109/PESGM.2012.6344997

[13] Katiraei, F. and Iravani, M.R. (2006) Power Management Strategies for a Microgrid with Multiple Distributed Generation Units. IEEE Transactions on Power Systems, 21, 1821-1831. https://doi.org/10.1109/TPWRS.2006.879260

[14] Popovic, D.S. and Boskov, E.E. (2008) Advanced Fault Management as a Part of Smart Grid Solution. CIRED Seminar 2008: SmartGrids for Distribution, Frankfurt, 23-24 June 2008, 23-24. https://doi.org/10.1049/ic:20080460

[15] Samanta, S., Bera, J. and Sarkar, G. (2014) An Approach for Power System Fault Diagnosis Using Current Samples towards Smart Grid Operation. Proceedings of the 2014 International Conference on Control, Instrumentation, Energy and Communication (CIEC), Calcutta, 31 January-2 February 2014, 743-746. https://doi.org/10.1109/CIEC.2014.6959189

[16] Dhend, M.H. and Chile, R.H. (2016) Efficient Fault Diagnosis in Smart Grid Using Non Conventional Mother Wavelet Function. 2016 IEEE PES Asia-Pacific Power and Energy Engineering Conference (APPEEC), Xi'an, China, 25-28 October 2016, 342-347. https://doi.org/10.1109/APPEEC.2016.7779524 
[17] Ntalampiras, S. (2018) Fault Diagnosis for Smart Grids in Pragmatic Conditions. IEEE Transactions on Smart Grid, 9, 1964-1971. https://doi.org/10.1109/TSG.2016.2604120

[18] Reddy, M.J.B., Rajesh, D.V., Gopakumar, P. and Mohanta, D.K. (2014) Smart Fault Location for Smart Grid Operation Using RTUs and Computational Intelligence Techniques. IEEE Systems Journal, 8, 1260-1271. https://doi.org/10.1109/JSYST.2014.2303833

[19] Korada, P. and Devidas, A.R. (2016) Studying the Impact of AC-Microgrid on the Main Grid and It's Fault Analysis. 2016 Biennial International Conference on Power and Energy Systems: Towards Sustainable Energy (PESTSE), Bangalore, 21-23 January 2016, 1-6. https://doi.org/10.1109/PESTSE.2016.7516526

[20] Glover, J.D., Sarma, M.S. and Overbye, T. (2012) Power System Analysis \& Design. SI Version, Cengage Learning, Boston.

[21] Mishra, M. and Rout, P.K. (2018) Detection and Classification of Micro-Grid Faults Based on HHT and Machine Learning Techniques. IET Generation, Transmission \& Distribution, 12, 388-397. https://doi.org/10.1049/iet-gtd.2017.0502

[22] Batiyah, S., Zohrabi, N., Abdelwahed, S. and Sharma, R. (2018) An MPC-Based Power Management of a PV/Battery System in an Islanded DC Microgrid. 2018 IEEE Transportation Electrification Conference and Expo (ITEC), Long Beach, CA, 13-15 June 2018, 231-236. https://doi.org/10.1109/ITEC.2018.8450155

[23] Zhang, W., Xiao, X., Zhou, K., Xu, W. and Jing, Y. (2017) Multicycle Incipient Fault Detection and Location for Medium Voltage Underground Cable. IEEE Transactions on Power Delivery, 32, 1450-1459. https://doi.org/10.1109/TPWRD.2016.2615886

[24] Dubey, H.C., Mohanty, S.R. and Kishore, N. (2011) Abrupt Change Detection of Fault in Power System Using Independent Component Analysis. 2011 International Conference on Signal Processing, Communication, Computing and Networking Technologies (ICSCCN), Thuckafay, 21-22 July 2011, 659-664. https://doi.org/10.1109/ICSCCN.2011.6024633

[25] Kim, C. (2009) Detection and Location of Intermittent Faults by Monitoring Carrier Signal Channel Behavior of Electrical Interconnection System. 2009 IEEE Electric Ship Technologies Symposium, Baltimore, 20-22 April 2009, 449-455. https://doi.org/10.1109/ESTS.2009.4906550

[26] Teymoor, G. (2015) Kalman Filter Based Incipient Fault Detection Method for Underground Cables. IET Generation, Transmission \& Distribution, 9, 1988-1997. https://doi.org/10.1049/iet-gtd.2015.0040

[27] Yaramasu, A., Cao, Y., Liu, G. and Wu, B. (2015) Aircraft Electric System Intermittent Arc Fault Detection and Location. IEEE Transactions on Aerospace and Electronic Systems, 51, 40-51. https://doi.org/10.1109/TAES.2014.120556

[28] Formica, T.J., Khan, H.A. and Pecht, M.G. (2017) The Effect of Inverter Failures on the Return on Investment of Solar Photovoltaic Systems. IEEE Access, 5, 21336-21343. https://doi.org/10.1109/ACCESS.2017.2753246

[29] Khademlahashy, A., Mehta, G., Li, L. and Zhu, J. (2017) Impact of Using Current Limiting Reactor on the Existing Circuit Breakers in Micro-Grids. 201720 th International Conference on Electrical Machines and Systems (ICEMS), Sydney, 11-14 August 2017, 1-5. https://doi.org/10.1109/ICEMS.2017.8056091

[30] Su, H.C., Chang, G.W., Liu, B.W., Chen, J.H., Jen, K.K., Chung, C.H. and Wu, J.Z. (2012) Modeling and Simulation for Grid Fault Impacts on a DC Microgrid. 2012 International Symposium on Computer, Consumer and Control, Taichung, Taiwan, 
4-6 June 2012, 373-376. https://doi.org/10.1109/is3c.2012.101

[31] Ge, L., Qu, L., Zhu, L., Chen, N. and Zhang, L. (2017) Impact of Fault-Ride-Through Strategy on Dynamic Characteristics of Photovoltaic Power Plant. The Journal of Engineering, 2017, 2130-2134. https://doi.org/10.1049/joe.2017.0706

[32] Kabir, S., Amin, A.A., Anayatullah, M., Saha, B.K. and Aziz, T. (2014) Impact of Supercapacitor Placement in Renewable Integrated Microgrid to Minimize Post-Fault Frequency Fluctuation. 2014 International Conference on Electrical Engineering and Information Communication Technology, Dhaka, Bangladesh, 10-12 April 2014, 1-5. https://doi.org/10.1109/ICEEICT.2014.6919063

[33] Arif, S. and Aziz, T. (2017) Impact of Battery Energy Storage System on Post-Fault Frequency Fluctuation in Renewable Integrated Microgrid. 2017 International Conference on Electrical, Computer and Communication Engineering (ECCE), Cox's Bazar, Bangladesh, 16-18 February 2017, 594-598. https://doi.org/10.1109/ECACE.2017.7912974

[34] Athari, M.H. and Wang, Z. (2018) Impacts of Wind Power Uncertainty on Grid Vulnerability to Cascading Overload Failures. IEEE Transactions on Sustainable Energy, 9, 128-137. https://doi.org/10.1109/TSTE.2017.2718518

[35] Lu, S., Phung, B.T. and Zhang, D. (2017) Study on DC Series Arc Fault in Photovoltaic Systems for Condition Monitoring Purpose. 2017 Australasian Universities Power Engineering Conference (AUPEC), Melbourne, Victoria, 19-22 November 2017, 1-6. https://doi.org/10.1109/AUPEC.2017.8282464

[36] Morlier, A., Siebert, M., Kunze, I., Mathiak, G. and Kntges, M. (2017) Detecting Photovoltaic Module Failures in the Field during Daytime with Ultraviolet Fluorescence Module Inspection. IEEE Journal of Photovoltaics, 7, 1710-1716. https://doi.org/10.1109/JPHOTOV.2017.2756452

[37] He, C., Mu, L. and Wang, Y. (2017) The Detection of Parallel Arc Fault in Photovoltaic Systems Based on a Mixed Criterion. IEEE Journal of Photovoltaics, 7, 1717-1724. https://doi.org/10.1109/JPHOTOV.2017.2742143

[38] Karthikeyan, S.P., Palanisamy, K., Raglend, I.J. and Kothari, D.P. (2009) Impact of Fault and Its Effect on Reactive Power in Power Evacuation from Wind Turbines. 2009 Asia-Pacific Power and Energy Engineering Conference, Wuhan, 27-31 March 2009, 1-4. https://doi.org/10.1109/APPEEC.2009.4918414

[39] Wang, L., Zhang, Z., Long, H., Xu, J. and Liu, R. (2017) Wind Turbine Gearbox Failure Identification with Deep Neural Networks. IEEE Transactions on Industrial Informatics, 13, 1360-1368. https://doi.org/10.1109/TII.2016.2607179

[40] Jiang, H., Dai, X., Gao, D.W., Zhang, J.J., Zhang, Y. and Muljadi, E. (2016) Spatial-Temporal Synchrophasor Data Characterization and Analytics in Smart Grid Fault Detection, Identification, and Impact Causal Analysis. IEEE Transactions on Smart Grid, 7, 2525-2536. https://doi.org/10.1109/TSG.2016.2552229

[41] Milioudis, A.N., Andreou, G.T. and Labridis, D.P. (2012) Enhanced Protection Scheme for Smart Grids Using Power Line Communications Techniques-Part I: Detection of High Impedance Fault Occurrence. IEEE Transactions on Smart Grid, 3, 1621-1630. https://doi.org/10.1109/TSG.2012.2208987

[42] He, M. and Zhang, J. (2011) A Dependency Graph Approach for Fault Detection and Localization towards Secure Smart Grid. IEEE Transactions on Smart Grid, 2, 342-351. https://doi.org/10.1109/TSG.2011.2129544

[43] Calderaro, V., Hadjicostis, C.N., Piccolo, A. and Siano, P. (2011) Failure Identification in Smart Grids Based on Petri Net Modeling. IEEE Transactions on Industrial Electronics, 58, 4613-4623. https://doi.org/10.1109/TIE.2011.2109335 
[44] Wang, N., Aravinthan, V. and Ding, Y. (2014) Feeder-Level Fault Detection and Classification with Multiple Sensors: A Smart Grid Scenario. 2014 IEEE Workshop on Statistical Signal Processing (SSP), Gold Coast, 29 June-2 July 2014, 37-40. https://doi.org/10.1109/SSP.2014.6884569

[45] He, Q. and Blum, R.S. (2011) New Hypothesis Testing-Based Methods for Fault Detection for Smart Grid Systems. 2011 45th Annual Conference on Information Sciences and Systems, Baltimore, 23-25 March 2011, 1-6. https://doi.org/10.1109/CISS.2011.5766150

[46] Pasdar, A.M., Sozer, Y. and Husain, I. (2013) Detecting and Locating Faulty Nodes in Smart Grids Based on High Frequency Signal Injection. IEEE Transactions on Smart Grid, 4, 1067-1075. https://doi.org/10.1109/TSG.2012.2221148

[47] Guillen, J.D.C. (2015) Fault Location Identification in Smart Distribution Networks with Distributed Generation. Thesis, Florida State University, Tallahassee.

[48] Kezunovic, M. (2011) Smart Fault Location for Smart Grids. IEEE Transactions on Smart Grid, 2, 11-22. https://doi.org/10.1109/TSG.2011.2118774

[49] (2015) IEEE Guide for Determining Fault Location on AC Transmission and Distribution Lines. IEEE Std C37.114-2014 (Revision of IEEE Std C37.114-2004), January $2015,1-76$.

[50] Khan, U.-A., Lee, S.-H., Seong, J.-K. and Lee, B.-W. (2010) Modeling and Simulation Using Simulink and Simpowersystem of Optimized HTS FCL Location in a Smart Grid Having a Wind Turbine Connected with the Grid. Progress in Superconductivity and Cryogenics, 12, 17-20.

[51] Xiao, Y. and Agbossou, K. (2009) Interface Design and Software Development for PEM Fuel Cell Modeling Based on Matlab/Simulink Environment. 2009 WRI World Congress on Software Engineering, Xiamen, 19-21 May 2009, 318-322. https://doi.org/10.1109/WCSE.2009.344

[52] Jianna, O., Shuo, L. Weidong, C. and Min, G. (2018) Modeling and Analysis of Microgrid Cluster Simulation Based on RTDS. 2018 2nd IEEE Conference on Energy Internet and Energy System Integration (EI), Beijing, 20-22 October 2018, 1-5. https://doi.org/10.1109/EI2.2018.8582121

[53] Babaei, M., Jafari-Marandi, R. and Abdelwahed, S. (2016) Real-Time Implementation of MVDC Shipboard Power System Reconfiguration. 2017 IEEE Electric Ship Technologies Symposium (ESTS). Arlington, 14-17 August 2017, 514-519. https://doi.org/10.1109/ESTS.2017.8069330

[54] Jeon, J.-H., Kim, J.-Y., Kim, S.-K., Ahn, O.-B. and Park, J. (2008) Development of HILS (Hardware In-Loop Simulation) System for MMS (Microgrid Management System) by Using RTDS. 2008 13 th International Power Electronics and Motion Control Conference, Poznan, 1-3 September 2008, 2492-2497.

https://doi.org/10.1109/epepemc.2008.4635638

[55] Yang, H., Touria, E. and Edrington, C. (2016) Real-Time Sensor Fault Detection and Isolation in Power System with Hardware Implementation. 2016 North American Power Symposium (NAPS), Beijing, 18-20 September 2016, 1-5.

https://doi.org/10.1109/NAPS.2016.7747936 